\title{
Synergies and trade-offs between sustainable development goals and targets: innovative approaches and new perspectives
}

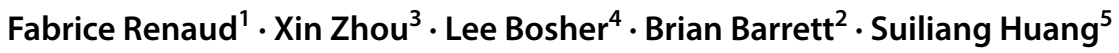

Published online: 23 May 2020

(c) Springer Japan KK, part of Springer Nature 2020

\section{Introduction}

The sustainable development goals (SDGs) adopted by the United Nations on 25 September 2015 are currently driving most development policies globally. With 17 goals, 169 targets, and 232 indicators to monitor and track progress, countries may lose sight of the synergies and trade-offs between goals and between targets, a fact that has been acknowledged from the beginning. To address this concern, approaches are being developed to identify and quantify these synergies and trade-offs. Most of these approaches address the national scale, as it is at this level that the SDGs are to be reported, but synergies and trade-offs are also relevant at the global and sub-national scales where, arguably, less research is underway.

Understanding the synergies and trade-offs between goals and targets is extremely important to (1) minimize trade-offs and maximize synergies, (2) avoid wasting resources, and (3) ensure equitable partnerships and ultimately, equitable development internationally, at the national scale and within countries. Research in this field is rapidly increasing and this is an opportune time to take stock of recent advances.

\section{Scope of this special feature}

The proposed special feature will give an opportunity to assess recent progress made in understanding synergies and trade-offs between goals and between targets. The special feature aims to include:

Fabrice Renaud

Fabrice.Renaud@glasgow.ac.uk

University of Glasgow, Dumfries, UK

2 University of Glasgow, Glasgow, UK

3 Institute for Global Environmental Strategies, Hayama, Japan

4 Loughbourough University, Loughbourough, UK

5 Nankai University, Tianjin, China
- new theoretical and conceptual frameworks stemming from different disciplinary and geographic perspectives;

- recent/emerging debates about the synergies and tradeoffs between the SDGs (e.g. how sustainability is related or not to the resilience and disaster risk reduction agendas);

- new comprehensive approaches and tools that allow for an analysis of synergies and trade-offs;

- stakeholder and community engagement for raising awareness;

- case studies of synergies and trade-off analysis and applications.

\section{Deadline, submission, and review process}

Please submit extended abstracts (maximum 500 words) to Fabrice.Renaud@glasgow.ac.uk by 30 October 2020. The extended abstracts should include a proposed paper title, the names and affiliations of all co-authors, the email address of the corresponding author, and one sentence indicating which components of the call's scope the paper aims to address. All this information does not count towards the word limit of the abstract. After review of the abstracts, a selection of proposed papers will be invited to submit full-length manuscripts through the journal's electronic editorial management system. Notification to all authors will be sent by 20 November 2020. Full paper submission deadline is 31 March 2021.

Author guidelines https://www.springer.com/environmen t/environmental+management/journal/11625?detailsPag e=pltci_728046.

Publisher's Note Springer Nature remains neutral with regard to jurisdictional claims in published maps and institutional affiliations. 